\title{
IMPACT OF RATIONAL EMOTIVE BEHAVIOR THERAPY (REBT) ON THE MANAGEMENT OF SUICIDAL IDEATION AND DEPRESSIVE TENDENCY AMONG INMATES IN CORRECTIONAL CENTER IN NSUKKA EDUCATION ZONE, NIGERIA
}

\author{
IREMEKA FELICIA UKAMAKA, AMAEZE FIDELIS EZE, EDE AUGUSTINA OBIOMA*, ISELIBO NWAMARA, \\ CHUKWUJI CHIOMA
}

\author{
Department of Educational Foundation, University of Nsukka, Nigeria \\ *Email: precisedfidelis@yahoo.com
}

Received:18 November 2020, Revised and Accepted: 12 December 2020

\begin{abstract}
The problem of ineffective and inefficient rehabilitation of inmates as well as in reducing their high rates of unprecedented unwholesome behaviors informed this study. Two research questions were answered and two hypotheses were tested. The study was a quasiexperimental study that adopts pre-test and posttest control group design. The treatment session lasted for a period of 12 weeks representing 24 sessions. The study was able to identify 35 inmates with depressive tendencies and suicidal ideation. Out of the 35 consent forms distributed to 35 inmates with depressive tendencies and suicidal ideation, 20 consent forms were returned showing interest in the study. Beck Scale for Suicide Ideation (BSS) developed in 1991 with a self-report of 21 items was used for data collection with reliability ranging from $\alpha=.87$ to $\alpha=.89$ across samples. The Center for Epidemiology Study Depression Scale (CES-D) with 20 items developed by Radloff (1977) was used to measure depression of any population of people. The internal consistency reliability coefficient of 0.88 was computed for CES-D through Cronbach Alpha statistics. Mean and standard deviation were used to answer the research questions while Analysis of Covariance (ANCOVA) was used to test the null hypotheses at 0.05 level of significance. It was found that Rational Emotive Behavior Therapy (REBT) significantly improved the management of suicidal ideation and depressive tendency among inmates in correctional centers. It was concluded that REBT has been found to be significant in handling behaviuoral problems as well as in improving the management of suicidal ideation and depressive tendency among inmates in correctional centers. It was recommended that inmates should be given close monitoring by their supervisors and warders in order to emancipate them from self defeating perception, thoughts and feeling that could endanger their emotion. Counseling-psychologists and religious leaders should make it a point of duty to be rekindling hope freedom, future and belongingness.
\end{abstract}

Keywords: Rational Emotive Behavioural Therapy (REBT), Management, Suicidal ideation, Depressive tendency.

2021 The Authors. Published by Innovare Academic Sciences Pvt Ltd. This is an open access article under the CC BY license (https://creativecommons.org/licenses/by/4.0/) DOI: https://dx.doi.org/10.22159/ijoe.2021v9i1.40622. Journal homepage: https://innovareacademics.in/journals/index.php/ijoe

\section{INTRODUCTION}

The depression is condition that affects mood, behavior, thought and attitude of a victim. Depression is a strong state of unhappiness, loss of concentration, inactive, and total disengagement of assigned responsibility (Caleb, 2018). Depression is an emotional state that is accompanied with poor self-worth, self-concept, self-efficacy, low self-worth and a state of dissatisfaction with self, environment and others (Amaeze, 2017). Depression is a body condition is manifests sleeplessness, aggression, dehumanization, depersonalization, trauma and mood swings (anxiety, bipolar, panic and psychoneurosis) (Amaeze, 2017). Depression is a very bad emotional condition or mood that can alter relations and instantly create enmity and instant quarreling among people working together of sharing the same goals and objectives (Caleb, 2018). Depression reduces the quality of life of any person ("American psychiatric association", 2020). It was reported that depression and it tendencies are not favourable to their victims because it leads to sorrowfulness, sadness, lost of hope, lack of trust, low-self image, low self-efficacy, depersonalization, pessimism and irritability ("American psychiatric association", 2020). The tendencies of being depressed cannot be easily be differentiated from a depressed personality. Lack of management of manifests depressive tendencies lead to depression and depressive moods (Amaeze, 2017).

The management of depressive tendencies is much easier than the management of a full blown depression ("American psychiatric association", 2020). Early signs and symptoms of depressive tendencies are very close to the depressive itself because all of them tend to affect the emotion, attitude, behavior, reasoning, association and perspective dispositions (Amaeze, 2017). It takes assiduous investment and commitment of strategies and skills of emotional experts and psychiatrics as well as other emotional and mental educators to identify people with depressive symptoms and signs (Caleb, 2018). People who are nurturing depressive tendencies tend to be manifesting loss of appetite, energy, vitality, pleasure, solitary behavior, lowered reasoning, lack of concentration to relevant issues, insomnia, aggression, rash decision making, irritation, among others that can affect the achievement of goals and objectives (Amaeze, 2017; "American psychiatric association", 2020). Depression is very terrible that it attacks one's psychology thereby leading to emotional problems. Emotion has been projected to be the foundation of every behavior (positive or negative). Depression is a product of depressive disorder and builds as a result of depressive tendency (Amaeze, 2017).

Some easily identifiable depressive symptoms by American Psychiatric Association (2020):

- $\quad$ Feeling sad or having a depressed mood

- Loss of interest or pleasure in activities once enjoyed

- Changes in appetite - weight loss or gain unrelated to dieting

- Trouble sleeping or sleeping too much

- Loss of energy or increased fatigue

- Increase in purposeless physical activity (e.g., inability to sit still, pacing, handwringing) or slowed movements or speech (these actions must be severe enough to be observable by others)

- $\quad$ Feeling worthless or guilty

- Difficulty thinking, concentrating or making decisions

- Thoughts of death or suicide

\section{BACKGROUND OF THE STUDY}

For depressive tendency to graduate to depression, symptoms must have been for a period that is not less than two weeks and 
must be linked to the recent mood swings (Chauhan et al., 2020; "American psychiatric association", 2020). Empirically, it has been proven that in a sample of 15 adults, one of them must be depressed or show greater manifestations of depressive tendencies in any given year (Chauhan, Gaur, Higgins, Lotha, Parweni, Promeet, Rogers, Sampolo, Singh, Sinha, \& Young, 2020; "American psychiatric association", 2020). It is also sacrosanct that six people $(16.6 \%)$ will not be exempted from depression at any quarter in their lifetime (Chauhan et al., 2020; "American psychiatric association", 2020). It has been reported that female women are prone to depressive tendencies and depression with a whooping number of them (40\%) being a victim of this ugly condition (Chauhan et al., 2020; "American psychiatric association", 2020). In Nigeria, it has been reported that inmates suffer depression and depressive conditions (Caleb, 2018). Most of them have attributed their sources of depression and depressive conditions to family obsession, inhuman treatment in the facilities, unhealthy environment, risky sexual advances and practices, poor medical conditions, underfeeding and lack of menstrual and sanitary materials (Ozioko, 2019).

Studies showed that most of the inmates have no coping strategies as a result of demeaned by their pent-up emotions and personality dispositions (Ozioko, 2019). This continued increase in depression and depressive tendencies will result to loss of lives, poor rehabilitation, poor career advancement, depersonalization, low self-esteem, low-self-efficacy, fighting, aggression, risky sexual behavior, high tendency to commit heinous crimes, social unrest, mood disorder bullying, irritability and suicide or suicidal ideation are most commonly noticed on the female inmates (Abiogun, 2019).

Suicide could be seen as the act of forcefully taken one's own life as a result of psycho-social unattainable or unaddressed pressing issues. It can also be seen as a drastic and rash decision taken to take own life in order to escape from constant oppressing issues of life mostly when it appears there is no hope of survival or escape (Abiogun, 2019). Suicide has been identified to contribute to the alarming rate of deaths recorded across the country (Psychology, 2020). Suicide has been ranked as the $11^{\text {th }}$ major leading factor that leads to death in 2002 which has the capacity to exterminate the life of more than 31,655 individuals which could be subject to the level of depression, oppression and social and biological demands in each of the years (Psychology, 2020). Suicidal is intentional. It is planned and executed. It is the act and process of taking one's life by self by force.

Suicide is proposed to be a result of suicidal ideation. Suicidal ideation is the thoughts and decisions that one is nurturing about imminent situation and perception of such. Suicidal ideation springs up suicidal attempts. The crux therefore is that suicidal ideation is the driving force of suicidal attempt or suicide as the case may be. Report has it that suicidal ideation is more common more than ever than attempt and suicide itself (Psychology, 2020). Suicidal ideation differs between male inmates and female inmates (Psychology, 2020). Specifically, inmates in Nigeria tend to record high suicidal attempts and ideations than suicidal completion (Abiogun, 2019). The issue of concern is that suicidal ideation is the mother of suicidal completion. Suicidal ideation whether not attempted or completed is detrimental to the health, physical, emotional and spiritual well-being of such a victim. Suicidal ideation is strong desire that drives or pushes one to have self dead. It is as a result of self defeating thoughts and feelings that are unfounded and unjustifiable.

Suicidal ideation is the disturbing state of act of not wishing self well. Suicidal ideation involves strong negative expectations and perceptions of immediate and future lifestyle. It is shredded with mystifications of why life is very sordid and unbearable. People with suicidal thoughts and ideations are supposed to be helped out of the situation and brought to realities of life. This state of suicidal ideation required great deal of behavioural and cognitive repositioning. Based on this backdrop, the researchers are proposing that Rational Emotive Behavioural Therapy (REBT) which has worked in handling other behavior and cognitive problems across different population can be very effective in managing depressive tendencies and suicidal ideations among a sample of prison inmates.

REBT is behavioural-cognitive therapy by Albert Ellis in 1955 that can be used to help clients who have self-defeating thoughts and behaviours. It is believed that REBT can actively dispute adaptive and suicidal thoughts and beliefs that can impact negatively on one's emotion (Eliis, 1962). REBT has been proposed to be relevant in the reduction of some irrational thoughts and beliefs (Khaledian, Saghafi, Moradi \& Khairkhah, 2013). It is believed that suicidal ideation is a problem of decreased irrational thoughts and perceptions (Ellis, 2003), mood and cognitive distortions (Shafie-Abadi \& Naseri, 2001; Khaledian, Saghafi, Moradi \& Khairkhah, 2013).

\section{SIGNIFICANCE OF THE STUDY}

The findings of this study would help the government, Nigerian prisons, inmates and counseling-psychologists in various ways:

1. The government and society would have a situation where the actual targeted rehabilitations would occur in the inmates leading to reduced negative thoughts and unwholesome behaviours.

2. The prisons supervisors and warders would find it very easy to manage inmates in their facilities due to reduced emotional problems and self-defeating thoughts.

3. The counseling-psychologists can effectively and efficiently help inmates to come out of their depressive tendencies and suicidal ideations by using the principles and manuals of REBT.

\section{AIM AND OBJECTIVES}

The study was aimed at investigating the efficacy of REBT in managing depressive tendencies and suicidal ideations among a sample of prison inmates. Specifically, the study sought to:

1. Find out the effect of REBT in the management of depressive tendencies among a sample of prison inmates based on their pretest and posttest scores.

2. Determine the effect of REBT in the management of suicidal ideation among a sample of prison inmates based on their pretest and posttest scores

\section{RESEARCH QUESTIONS}

The following research questions posed were answered in this study.

1. What is the effect of REBT in the management of depressive tendencies among a sample of prison inmates based on their pretest and posttest scores?

2. What is the effect of REBT in the management of suicidal ideation among a sample of prison inmates based on their pretest and posttest scores?

\section{HYPOTHESES}

The following hypotheses were tested at 0.05 level of significance.

1. REBT in not effective in the management of depressive tendencies among a sample of prison inmates based on their pretest and posttest scores.

2. REBT in not effective in the management of suicidal ideation among a sample of prison inmates based on their pretest and posttest scores.

\section{METHODOLOGY}

The study was a quasi-experimental study that adopts pre-test and posttest control group design. This design is appropriate mostly when randomization of subjects to groups seem impossible (Nworgu, 2015). The symbols for the experiment are represented as shown below. 
Table 1: The symbols for the experiment

\begin{tabular}{|c|c|c|c|}
\hline Group & Pre-test & $\begin{array}{c}\text { REBT- } \\
\text { treatments }\end{array}$ & Post-test \\
\hline $\begin{array}{c}\text { Experimental } \\
\text { group (EG) }\end{array}$ & $\mathrm{O}_{1}$ & $\mathrm{X}$ & $\mathrm{O}_{2}$ \\
\hline $\begin{array}{c}\text { Control } \\
\text { group (CG) }\end{array}$ & $\mathrm{O}_{1}$ & - & $\mathrm{O}_{2}$ \\
\hline
\end{tabular}

Legends: $\mathrm{O}_{1}$ - Pre-test for the two groups, $\mathrm{O}_{2}$ - Post-test for the two groups. X- REBT treatment

The treatment session lasted for a period of 12 weeks representing 24 sessions. Before the treatment, the participants were shared into the experimental (10participants) and control groups (10-participants). They were given pre-test (Time1) before the treatment. The researchers and assistants met with the inmates two times (two sessions) in a week for a period of 12 weeks. Each of the sessions lasted for 45 minutes. The first contact in the first week was introduction and exchange of pleasantries. The second, third and fourth weeks, they were asked to identify the various suicidal ideations and depressive tendencies nurtured. In the fifth and sixth weeks, they were told why these thoughts are affecting their behaviours. In the seventh, eighth ninth, tenth and eleventh weeks, they were told on how to dispute, demystify, change their reasoning abilities, critical reflection on issues, perspective disposition and building of hopes. Each of the sessions were accompanied by evaluation and self report. The last session in the last week was brought the treatment to an end. The treatment was only given to those in the experimental group. After the treatment, post-test (Time2) was administered to the two groups.

The study was able to identify 35 inmates with depressive tendencies and suicidal ideation. Out of the 35 consent forms distributed to 35 inmates with depressive tendencies and suicidal ideation, 20 consent forms were returned showing interest in the study. A consent form of participation in the study was given to the inmates their hall wardens and supervisors. The inclusive criteria for selection are the one highlighted by American Psychiatric Association which are (1) feeling sad or having a depressed mood, (2) loss of interest or pleasure in activities once enjoyed, (3) changes in appetite, (4) trouble sleeping (5) increased fatigue (6) increase in purposeless physical activity (e.g., inability to sit still, pacing, handwringing) or slowed movements or speech (these actions must be severe enough to be observable by others) (7) feeling worthless or guilty (8) difficulty thinking, concentrating or making decisions, (9) and wishing to die. The exclusive criteria are (1) those who did not return the consent form (2) those that are about leaving the facilities before the study (4) those who serve as counselors and religious preachers to other inmates. Two instruments were used for data collection in this study. The first was Beck Scale for Suicide Ideation (BSS) developed in 1991 has a self-report of 21 items. The instrument was structured with response options of 0,1 and 2 with increasing severity determined by the choice of responses. In rating, 0 is rated the lowest followed by 1 and 2 as the highest severity of suicidal ideation.

Some sample items are (1) I have no desire to kill myself (2) I have a moderate to strong desire to kill myself, among others. The instrument is designed for people above 17 years of age which is an acceptable age before one can be incarcerated in Nigeria. The BSS has proven to be a reliable measure across many different settings and samples, showing good internal consistencies e.g. $\alpha=.87$ in an outpatient sample (Barnhofer, Crane, Hargus, Amarasingh, Winder \&Williams, 2009), $\alpha=.89$ in a risk sample (Crane, Barnhofer, Duggan, Eames, Hepburn, Shah \& Williams, 2014), and $\alpha=.88$ in a non-clinical student sample (Hirsch \& Conner, 2016).

The original version of BSS modified to suit the content of the research locale in order to remove culture bias. Confirmatory factor analysis showing was used to revalidate the scale after the items were reviewed down to 15 because of the complexity of the respondents. The internal consistency reliability coefficient of 0.89 was established for BSS through Cronbach Alpha.

The Center for Epidemiology Study Depression Scale (CES-D) developed in 1977 by Radloff. It can be used to measure depression of any population of people. CES-D is a self-report scale with 20 items structured on a four point rating scale. The scale has been proven to be valid and reliable across studies. The researchers modified the scale in order to suit the study population of inmates with a 10 items. The CES-D was structured with response options of strongly agree (4) to strongly disagree (1). The higher the response on the response format, the higher the severity of depressive tendency. Face and content validities were ensured. The internal consistency reliability coefficient of 0.88 was computed for CES-D through Cronbach Alpha statistics. Mean and standard deviation were used to answer the research questions while Analysis of Covariance (ANCOVA) was used to test the null hypotheses at 0.05 level of significance.

\section{RESULTS}

Research question 1: What is the effect of REBT in the management of depressive tendencies among a sample of prison inmates based on their pretest and posttest scores? Table 2 revealed that at the pretest level, the experimental and control groups had high mean values of 61.30 and 62.60 with standard deviation scores of 8.06 and 7.85. After treatment, the mean scores of the experiment and control groups reduced to 23.70 and 54.40 respectively. The study revealed that the depression was reduced by mean value of $-37.8(23.70-61.30)$ compared to the control group with mean reduction of -8.2 (34.40-62.60).

Table 2: Mean and standard deviation scores on the effect of REBT in the management of depressive tendencies

\begin{tabular}{|c|c|c|c|c|c|c|c|}
\hline \multirow{2}{*}{ Groups } & \multirow{2}{*}{$\mathbf{N}$} & \multicolumn{2}{|c|}{ Pre-test } & \multicolumn{2}{|c|}{ Post-test } & \multirow{2}{*}{ Mean loss } & $\begin{array}{c}\text { Loss score } \\
\text { difference }\end{array}$ \\
\cline { 3 - 6 } & & Mean & SD & Mean & SD & & \multirow{2}{*}{-29.6} \\
\hline $\begin{array}{c}\text { Experimental group } \\
\text { (Depressive tendency) }\end{array}$ & 10 & 61.30 & 8.06 & 23.70 & 2.41 & -37.8 & -8.2 \\
\hline Control group & 10 & 62.60 & 7.85 & 54.40 & 8.88 & & \\
\hline
\end{tabular}

Table 3: Mean and standard deviation scores on the effect of REBT in the management of suicidal ideation

\begin{tabular}{|c|c|c|c|c|c|c|c|}
\hline \multirow{2}{*}{ Groups } & \multirow{2}{*}{$\mathbf{N}$} & \multicolumn{2}{|c|}{ Pre-test } & \multicolumn{2}{c|}{ Post-test } & \multirow{2}{*}{ Mean loss } & $\begin{array}{c}\text { Loss score } \\
\text { difference }\end{array}$ \\
\cline { 3 - 7 } & & Mean & SD & Mean & SD & & \\
\hline $\begin{array}{c}\text { Experimental group } \\
\text { (Depressive tendency) }\end{array}$ & 10 & 60.50 & 5.68 & 22.10 & 3.07 & -38.4 & -30.2 \\
\hline Control group & 10 & 62.60 & 7.85 & 54.40 & 8.88 & -8.2 & \\
\hline
\end{tabular}


Research question 3: What is the effect of REBT in the management of suicidal ideation among a sample of prison inmates based on their pretest and posttest scores?

Table 3 revealed that at the pretest level, the experimental and control groups had high mean values of 60.50 and 62.60 with standard deviation scores of 5.68 and 7.85. After treatment, the mean scores of the experiment and control groups reduced to
22.10 and 54.40, respectively. The study revealed that the suicidal ideation was reduced by mean value of -38.4 (22.10 $60.50)$ compared to the control group with mean reduction of 8.2 (54.40-62.60).

Hypothesis 1: REBT is not effective in the management of depressive tendencies among a sample of prison inmates based on their posttest scores.

Table 4: ANCOVA on the effect of REBT in the management of depression tendencies

\begin{tabular}{|c|c|c|c|c|c|c|}
\hline \multicolumn{7}{|c|}{ Tests of between-subjects effects } \\
\hline \multicolumn{7}{|c|}{ Dependent variable: post-test } \\
\hline Source & $\begin{array}{c}\text { Type III sum of } \\
\text { squares }\end{array}$ & df & Mean square & $\mathbf{F}$ & Sig. & Partial eta squared \\
\hline Corrected model & $5005.385^{a}$ & 2 & 2502.692 & 90.607 & 0.000 & 0.914 \\
\hline Intercept & 17.000 & 1 & 17.000 & 0.615 & 0.444 & 0.035 \\
\hline Pre-test & 292.935 & 1 & 292.935 & 10.605 & 0.005 & 0.384 \\
\hline Groups & 4478.939 & 1 & 4478.939 & 162.154 & 0.000 & 0.905 \\
\hline Error & 469.565 & 17 & 27.621 & & & \\
\hline Total & 35973.000 & 20 & & & & \\
\hline Corrected total & 5474.950 & 19 & & & & \\
\hline
\end{tabular}

$\mathrm{a}-\mathrm{r}^{2}=0.914$ (Adjusted $\mathrm{R}$ squared $=0.904$ )

Table 4 showed that the degrees of freedom are 1 and 17 . With ANCOVA value (F) 162.154, the significant value of 0.000 is less than the probability value of 0.05 . Therefore, the hypothesis is rejected. Therefore, REBT made a significant effect between the experimental group and the control group. The effect of the treatment was very high as shown by Partial Eta Squared value of 0.905 .

Hypothesis 2: REBT in not effective in the management of suicidal ideation among a sample of prison inmates based on their pretest and posttest scores.

Table 5: ANCOVA on the effect of REBT in the management of suicidal ideation

\begin{tabular}{|c|c|c|c|c|c|c|}
\hline \multicolumn{6}{|c|}{ Tests of Between-Subjects Effects } & \multirow[b]{3}{*}{ Partial eta squared } \\
\hline \multicolumn{6}{|c|}{ Dependent variable: VAR00002 } & \\
\hline Source & $\begin{array}{l}\text { Type III sum of } \\
\text { squares }\end{array}$ & df & Mean square & $\mathbf{F}$ & Sig. & \\
\hline Corrected model & $5648.379^{a}$ & 2 & 2824.189 & 132.127 & 0.000 & 00.940 \\
\hline Intercept & 7.313 & 1 & 7.313 & .342 & 0.566 & 0.020 \\
\hline Pre-test & 431.929 & 1 & 431.929 & 20.207 & 0.000 & 0.543 \\
\hline Groups & 4622.114 & 1 & 4622.114 & 216.242 & 0.000 & 0.927 \\
\hline Error & 363.371 & 17 & 21.375 & & & \\
\hline Total & 35273.000 & 20 & & & & \\
\hline Corrected total & 6011.750 & 19 & & & & \\
\hline
\end{tabular}

$\mathrm{a}-\mathrm{r}^{2}=0.940$ (Adjusted R squared $=0.932$ )

Table 5 showed that the degrees of freedom are 1 and 17 . With ANCOVA value (F) 216.242, the significant value of 0.000 is less than the probability value of 0.05 . Therefore, the hypothesis is rejected. Therefore, REBT made a significant effect between the experimental and control groups. The effect of the treatment was very high as shown by Partial Eta Squared value of 0.927 .

\section{DISCUSSION}

It was found that REBT significantly improved the management of suicidal ideation and depressive tendency among inmates in correctional centers. The result has proven the efficacy of REBT in the management of behavioural and emotional problems. It there is continued increase in the level of depressive tendency and suicidal ideation among prison inmates, the noble and commendable purposes of rehabilitation will be completely defeated. This is because inmates in Nigeria tend to record high suicidal attempts and ideations than suicidal completion (Abiogun, 2019). The issue of concern is that suicidal ideation is the mother of suicidal completion. Suicidal ideation whether not attempted or completed is detrimental to the health, physical, emotional and spiritual well-being of such a victim. Suicidal ideation is strong desire that drives or pushes one to have self dead. It is as a result of self defeating thoughts and feelings that are unfounded and unjustifiable. The finding is supported by the fact that REBT can be effective in the disputation of unjustifiable cognitive and behavioural challenges (Caleb, 2018). REBT in this study was significant in reducing depressive tendencies and suicidal ideations because of its efficacy disputing the disturbing state of act of not wishing self well, strong negative expectations and perceptions of immediate and future lifestyle which are shredded with mystifications of why life is very sordid and unbearable. REBT was very significant and effective in the reduction and management of situations that can lead to loss of lives, poor rehabilitation, poor career advancement, depersonalization, low self-esteem, low-self-efficacy, fighting, aggression, risky sexual behavior, high tendency to commit heinous crimes, social unrest, mood disorder bullying, irritability and suicide or suicidal ideation (Abiogun, 2019).

\section{CONCLUSION}

Based on the findings of this study, it was concluded that REBT has been found to be significant in handling behaviuoral problems as well as in improving the management of suicidal ideation and depressive tendency among inmates in correctional centers.

\section{RECOMMENDATIONS}

1. It was recommended that inmates should be given close monitoring by their supervisors and warders in order to emancipate them from self defeating perception, thoughts and feeling that could endanger their emotion. 
2. Counseling-psychologists and religious leaders should make it a point of duty to be rekindling hope freedom, future and belongingness.

\section{ACKNOWLEDGEMENT}

Nil

\section{AUTHORS CONTRIBUTIONS}

Conception of the topic: Dr Amaeze, Fidelis, Eze, Dr Iremeka, Felicia Ukamaka, Ede, Augustina Obioma, and Isilebo Nwamara Editorial work: Dr Iremeka, Felicia Ukamaka and Isilebo Nwamara

Paper writing: Dr Amaeze, Fidelis Eze, Dr. Iremeka, Felicia Ukamaka, Ede, Augudtina Obioma and Isilebo, Nwamara Data analysis: Dr Amaeze, Fidelis Eze and Iselibo Nwamara Data collection: Dr Amaeze, Fidelis, Eze, Dr Iremeka, Felicia Ukamaka, Ede, Augustina Obioma, and Isilebo Nwamara

\section{CONFLICT OF INTEREST}

The authors declared that there was no form of conflict of interest that existed within them. The study was carried out and done collaboratively and in synergy.

\section{REFERENCES}

- Abiogun, P. H. (2019). Consequences of low self-esteem, low-self-efficacy and aggression on sexual risky sexual behavior. Journal of Counselling Psychology in Social Development, 1(1), 55-70.

- Amaeze, F. E. (2014). Evaluation of universal basic education in Imo State, Nigeria. (Unpublished masters dissertation), Faculty of Education, University of Port Harcourt, Nigeria.

- Amaeze, F. E. (2017). A causal model of psychological variables on Physics academic performance of senior secondary school students in Imo State, Nigeria. (Unpublished doctoral thesis), Faculty of Education, University of Port Harcourt, Nigeria.

- American Psychiatric Association (2020). What is depression? Retrieved November 11, 2020, from https://www.psychiatry.org/patients-

families/depression/what-is-depression.

- Beck, M. D., \& Aaron, T. (1991). Beck Scale for Suicide Ideation. Retrieved from https://www.pearsonassessments.com/store/usassessm ents/en/Store/Professional-Assessments/Personality\%26-Biopsychosocial/Beck-Scale-for-SuicideIdeation/p/100000157.html
- Barnhofer, T., Crane, C., Hargus, E., Amarasingh, M., Winder, R., \& Williams, J.M.G. (2009). Mindfulness-based cognitive therapy as a treatment for chronic depression: A preliminary study. Behaviour Research Therapy, 47(5), 366-373. doi.org/10.1016/j.brat.2009.01.019

- Caleb, O. L. (2018). Types, forms and causes of depression as correlates of human depersonalization act. Journal of Social Counselling, 1(1), 23-44.

- Chauhan, Y., Gaur, A., Higgins, J., Lotha, G., Parweni, N., Promeet, D., Rogers, K., Sampolo, M., Singh, S., Sinha, S., \& Young, G. (2020). Depression: Psychology. Retrieved from https://www.britannica.com/science/depressionpsychology

- $\quad$ Crane, C., Barnhofer, T., Duggan, D. S., Eames, C., Hepburn, S., Shah, D., \& Williams, J.M.G. (2014). Comfort from suicidal cognition in recurrently depressed patients. Journal of Affective Disorders, 155, 241-246. doi.org/10.1016/j.jad.2013.11.006

- Ellis, A. (1962). Reason and emotion in psychotherapy. Amherst, NY: Lyle Stuart.

- Ellis, A. (2003). Discomfort anxiety: A new cognitivebehavioural construct (Part I). Journal of Rational Emotive and Cognitive-Behaviour Therapy, 21(3), 183-191. doi.org/10.1023/A:1025881810501

- Hirsch, J. K., \& Conner, K. R. (2006). Dispositional and explanatory style optimism as potential moderators of the relationship between hopelessness and suicidal ideation. Suicide and Life-Threatening Behavior, 36(6), 661-669. doi.org/10.1521/suli.2006.36.6.661

- Khaledian, M., Saghafi, F., Moradi, S., \& Khairkhah, Z. (2013). Investigating the relationships of irrational beliefs with anxiety and their effect in two different academic systems in Iran. International Research Journal of Applied and Basic Sciences, 4(5), 1185-1191.

- Nworgu, B. G. (2015). Educational research: Basic issues and methodology (3rd ed.) Nsukka, Nigeria: University Trust Publishers.

- Ozioko, M. L. (2019). Strategic coping strategies in pentup emotions and personality dispositions. Journal of Counselling Psychology in Social Development, 1(1), 19-38.

- Psychology (2020). Suicide. Retrieved November 17, 2020, from http://psychology.iresearchnet.com/socialpsychology/antisocial-behavior/suicide/

- $\quad$ Radloff, L. S. (1977). The CES-D scale: A self-report report depression scale for research in the general population. Applied Psychological Measurement, 1(3), 385-401. doi.org/10.1177/014662167700100306

- Shafie-Abadi, A., \& Naseri, G. (2001). Counseling and psycho-treatment. University Publication Center. 